\title{
University and IT companies interaction of educational process of new IT specialists generation
}

\author{
Nikolay Volkov, Yury Lyamin \\ Scientific and educational department, \\ Voskhod, R\&D \\ Moscow, Russia \\ j.lyamin@voskhod.ru
}

\author{
Elena Romanova \\ Dept. of Automated organizational systems \\ Moscow Technological University (MIREA), \\ Moscow, Russia \\ porabot@inbox.ru
}

\begin{abstract}
Issues of education of new generation of IT specialists in Russia are the most important in the current changes in economic and technological development of the state. Existing technological requirements produce new professions and require extremely new forms of interaction between universities and business. The authors concern the issues of compliance of professional and educational standards for the needs of leading IT companies. A retrospective is considered and options for improving the interaction between IT companies and universities are suggested, based on the experience of MIREA and Voskhod.
\end{abstract}

Keywords - IT specialists, technological calls, professions, IT companies.

\section{INTRODUCTION}

Today, commercial organizations or state structures can not do without IT specialists. The information technology market is changing dynamically, and there is a constant need to forecast the demand for trained specialists.

At the highest level, it was repeatedly said that the country's IT industry as a whole suffers from a shortage of personnel. Now the industry employs about 300 thousand people. The labor market for IT professionals is practically unlimited in the near future and more specialists are being trained than educational institutions produce. [1] However, according to statistics, only $15-20 \%$ of graduates are immediately ready to start their duties, the rest must be educated by employers.

The traditional expression - qualified specialists - implies a wide range of activities, and as a basis, pays much attention to the educational process these specialists at all levels: primary, secondary and higher professional education. Now, the education structure of young people is such that they can become specialists only in production. In this regard, it is important for the company to understand its requirements to all levels of studies, beginning with working professions and ending with the management staff of employees.

For the last five years the Ministry of Labor of the Russian Federation has been actively pursuing the policy of professional professions, relying precisely on such aspirations of companies. It is planned to develop up to 800 standards. "The professional standard (PS) is a key mechanism for selfregulation of the labor market. It is a multifunctional regulatory document that establishes requirements within a particular type (area) of professional activity ". Such a large-scale update of the national system of qualifications of employees affects virtually all sectors of the Russian economy and the IT industry, respectively. For the IT industry, about 40 professions were declared, about 20 were approved. [2]

At the present stage of development of IT companies, especially those working on government orders, there is a presence in a wide range of short-term projects, which imposes certain requirements on the personnel involved. In this regard, there are several issues that are important for the development of the interaction between the companie and the university:

- definition of specific requirements and sufficient level of background for employees;

- establishing compliance of these requirements with professional and educational standards;

- identification of new activities.

The article considers the technological prospects that are fundamental for today's IT industry. Retrospective of the processes of cooperation between educational organizations and enterprises is given, main directions of development are revealed.

\section{MODERN IT TRENDS IN RUSSIA}

This year the Government of the Russian Federation adopted the program "Digital Economy of the Russian Federation", in which the data in digital form is defined as the most important factor of production in all spheres of the society's activity.

The program identified 5 main areas:

- Normative regulation.

- Education and staff.

- Formation of research competencies and technical reserves.

- $\quad$ IT infrastructure.

- Cybersecurity. 
Obviously, for the successful development of society in these areas, it is necessary to prepare a new generation of young specialists capable of responding to the technological challenges that are now facing the entire Russian IT community.

Among the main technological challenges from the leading countries are the following:

- Creation of a powerful digital infrastructure (based on supercomputer data centers, high-speed secure data networks, the latest solutions in the field of data storage systems). This in turn requires the resolution of issues related to power supply, which sharply increases the need to develop new technological materials and methods aimed at drastically reducing energy consumption in IT equipment.

- Creation of end-to-end technologies, including socalled large data, or big data, "non-traditional" computers based on the principles of fuzzy logic, decision support systems based on the latest achievements in neural networks, as well as other areas of artificial intelligence.

- Active penetration of the "Internet of things" and robotics to virtually all spheres of industrial and social activities of the society, the mismatch of "branded" and national standards in their interfaces, which entails both some technological threats and threats to the view of information security, since "combinational "Solutions are often vulnerable at the junctions.

- Increasing threats in the field of cyber security for IT infrastructures, both from informal structures and from state bodies of geopolitical opponents, facilitated by a certain "anonymity", available both in the Internet environment and in related areas such as IP telephony. The problem is also complicated by the inconsistency of legal and legislative aspects in various states, which also contributes to the relative "invulnerability" of cybercriminals.

All the above technological challenges require the accelerated development of industries that are associated not only with the re-creation of the domestic microelectronic industry, but also with the need to carry out research aimed at obtaining promising technical solutions. It is necessary to exclude the emergence of situations when the latest scientific achievements obtained by our scientists are realized, first of all, in developed foreign countries, to which there are a lot of examples in the recent past.

Similarly, cardinal solutions are required for the reform of the information technology industry. And here there are a number of problems that have already been partially encountered in the past, since the problem of answering the emerging technological challenges has always been in our country. Then these problems related to other industries, such as engineering, nuclear industry, rocket science. At the same time, a result was achieved that allows us to talk about the achievement of parity in our country in these areas with other leading states.
Proceeding from the above, it is necessary to look at these issues from the point of view of the state IT company, which is faced with the task of answering some technological challenges.

First of all, it is worth talking about the education system a new generation of specialists who must provide the necessary potential for this, and those educational and skills facilities where not only the preparation of young specialists, but also the re-profiling and restudying of working specialists.

\section{ASPECTS OF INTERACTION BETWEEN ORGANISATIONS AND UNIVERSITIES}

\section{A. Retrospective}

Let's consider in more detail the progressive development of interaction between companies and universities: the decisions that were taken in our country to provide study for professionals that needed production.

The first - the education system young professionals was divided into four levels. The first level - the preparation of skilled "workers" cadres was carried out in the system of "real schools" (in tsarist Russia), in the system of vocational schools (in the early USSR), in the vocational school system (in the late USSR). Their goal was to train skilled workers for enterprises. And it is not surprising that such schools were created directly in those industrial enterprises that needed these specialists. At the same time, often, specialists in "higher" qualifications who worked at enterprises were also involved in lead-up.

The second level - technical schools (tsarist Russia), technical schools (in the times of the USSR). Qualified specialists were trained, whose task was to provide technical support for the operation of a particular enterprise (taking into account its specificity and existing technical base). These specialists were supposed to have the general theoretical background necessary to understand the technical features of the equipment with which they are to work. It was also assumed that the most capable students can continue their further study in higher school, beginning with the third year. That is, after the technical school the level of theoretical background of graduates corresponded to the student of the university after the second course. Thus, emphasis was placed on the practical application of theoretical knowledge. Technical schools were often created at industrial enterprises, which were prepared for themselves by the average technical personnel.

The third level is higher education. At the same time, they were divided into two unequal groups. The first group universities as a classical form of higher education since the Middle Ages, the second - a technical and humanitarian universities, focused on a specific field of activity. A number of them continued the traditions of technical education with a standard level of general theoretical background for the first two years, followed by in-depth study of the subjects on which the university was specialized. It is characteristic that the program of the first two years in most technical universities coincided, which allowed students who, in the process of learning, realized that the university was chosen incorrectly, go to another institution without losing their studies time (of course, there were always exceptions to this rule). There were universities that worked within the Ministry of Higher 
Education, but there were also sectoral universities that trained specialists for a specific field of industry. Considering that enterprises, even those related to the same industry, can differ very much in their specifics, at some companies in the industrial sphere, so-called VTUZs were created in factories. Studies in them occurred in parallel with production activities and was focused on the specific scope of the enterprise. As a result, at the output of the young specialist not only knew his companie thoroughly, but he could also occupy engineering positions. Under such a scheme, studies was provided in such branches as engineering, aircraft building and the like, where "industrial" engineers were needed who headed the work collectives.

For new industries that appeared in the second half of the twentieth century, such as radio electronics, microelectronics, computers, this approach could not be copied directly, since the role of the "engineer" in these areas is different. In particular, the rate of change in the material base is many times higher than in traditional industry, which leads to the senselessness of a long study of the existing infrastructure, since by the time it ends, it will certainly become obsolete. It was more important to lay common basic knowledge, allowing the graduate to independently understand the specifics of the activities that his employer needs.

One of the directions of the coordinated activity on background specialists in the above mentioned sectors was the creation of the mechanism of "basic chairs" with the leading organizations - developers in these industries. It was assumed that starting from the 3-4th year students, along with studying general courses at the university, will be trained a few days a week directly at company, studying "specialized" or "professional" courses specific to the field of activity in which specialized enterprise. At the same time, both practical scientists and highly qualified specialists employed in the enterprise were involved in teaching activities. Given that the production base of universities and companies differed sufficiently strongly, this allowed the student to gain experience in practical work with the latest equipment and get acquainted with the latest research being conducted in the organization.

The experience of the basic departments showed that this approach made it possible not only to shorten the time necessary for a young specialist to understand the specifics of his upcoming work, but also to get acquainted with the team in which he is to work. In addition, with the appearance of this specialist's desire to continue his further education, the basic departments served as a natural bridge to postgraduate study at the university. In particular, the basic department of the Sunrise successfully operates in the current conditions, creating the necessary conditions for vocational guidance of students.

Today, according to the order of the Ministry of Education and Science of the Russian Federation) from March 6, 2013, No. 159, the main form of interaction between business structures and education is still the basic department created "with the aim of improving the quality of education by using the results of scientific research work, and the achievements of science and technology, the expansion of the research principle of education and the scientific component of educational activities, including the involvement of students in the conduct of scientific research under the hands dstvom scientists, staffing, scientific research."

The fourth level is postgraduate and doctoral studies aimed at preparation scientific personnel focused on performing research in the chosen field, searching for new solutions and new applied areas. This is personnel that are necessary to meet the technological challenges, so the teaching of graduates of IT universities that can reach this level of education should become a priority.

\section{B. Development of departments at enterprises}

Consider the raised problem from the point of view of IT companies. The projects with which most IT companies operate, should be divided into two groups.

The first group is short-term projects, designed for a period of several months and up to one year.

The second is long-term permanent projects related to large state systems that are associated with the formation of a single information space of the country.

Each group has its own specificity, which requires different types of specialization. In practice, it is difficult to use young specialists in short-term projects, since the process of profiling and entering the project requires, as a rule, time comparable to the duration of the entire project. Graduates come to work in the autumn, when work on short-term projects is at the peak or final stage. As a result, HR services are forced to make their choice not among graduates, but among already formed professionals, attracting them for a short period of time to work on a specific project.

The projects of the second group are of a long-term nature (several years) and are in a state of constant development and modification. Involvement of young professionals to such work is more justified, since it allows them to actively use them in work on projects on a long-term basis after their profiling. In this you can see the increasing role of the core departments of the IT companies for the process of preparing senior students by engaging in work on specific projects. This should include classes aimed at detailed acquaintance with the real projects of the enterprise, which allows to reconcile the theoretical knowledge received by students in the university with their practical use. Its role is played by internships and production practices conducted with the involvement of the development and design departments of IT company.

Such an approach to education and profiling at the basic department can expand the possibility of attracting young specialists and working on the projects of the first group, but there is a fairly large list of problems associated with higher education. Unfortunately, current graduates of university, as a rule, do not possess the required competences. The reasons for this are related both to the specifics of the projects being implemented at the enterprise, and to the mismatch of professional standards for IT professionals and State educational standards. These standards practically do not concern such areas as the processing of "big data", "Internet of things", "cloud technologies", "decision making in conditions of uncertainty", etc. This leads to the fact that the company is 
forced to develop its own, local requirements to specialists in these areas. Therefore, the task of the basic departments is to ensure interaction between the university and the enterprise in developing exactly the professional standards that are necessary in the industry today. Much has been said about this recently and there are hopes that a positive shift in this area will finally be achieved.

\section{Factors influencing the generation specialists}

According to the data of the portal HH.RU on September 2017, the index of demand for vacancies by applicants in the field of Information Technology, Internet and Telecom was 2.9. This index shows the scarcity of specialists through the ratio of the number of active resumes to vacancies. The lower the index, the lower the competition among applicants in this area. Studying the ratio of vacancies and resumes for all regions of Russia, there is a decreasing dynamics in the number of summaries compared to the previous year (Table 1). [3]

TABLE I. INDEX HH.RU

\begin{tabular}{|l|c|c|c|l|l|}
\hline $\begin{array}{l}\text { Professional } \\
\text { area. }\end{array}$ & $\begin{array}{l}\text { Dynamics } \\
\text { of } \\
\text { vacancies }\end{array}$ & $\begin{array}{l}\text { Resume } \\
\text { dynamics }\end{array}$ & Index & $\begin{array}{l}\text { Proposed } \\
\text { salary, } \\
\text { rub }\end{array}$ & $\begin{array}{l}\text { Applicant } \\
\text { sex m / f }\end{array}$ \\
\hline $\begin{array}{l}\text { Information } \\
\text { technology, } \\
\begin{array}{l}\text { Internet and } \\
\text { telecom }\end{array}\end{array}$ & $9 \%$ & $4 \%$ & 3,1 & 58640 & $\begin{array}{c}81 \% / \\
19 \%\end{array}$ \\
\hline
\end{tabular}

There are other problems in the field higher school from the point of view of the IT company, some of which are listed below.

\section{Teaching staff}

On the one hand, there is a clear lack of highly skilled practical teachers, especially practical scientists, who could fill the curriculum with the necessary practical information. On the other hand, non-competitive wages and a low prestige of the teaching profession lead to a shortage of teaching staff and widen the gap between the proposed knowledge and the opportunity to use them in real life. At the same time, the rate of technology update aggravates this process.

2. Insufficient support of the basic departments by the business community.

On the one hand, universities are open for interaction with business, it is possible to organize basic departments, saturate the program with practical classes, organize internships, modernize teaching materials, etc. On the other hand, the basic department is quite a costly exercise. Employees teach during working hours, spend extra time. This is a fairly large resource, including financial investments. In addition, highly qualified specialists are quite an expensive resource for the company. Their main task is not to teach, but in time to produce products with which companies compete in the market. The learning process is important, but it is an auxiliary task. The company is not interested in keeping professional teachers in the staff, whose task is only teaching, they are all the leading developers. There is a conflict of interests. If the organization has its own training center, then it works according to its own program, which does not correspond to the program of universities. In addition, there are no mechanisms for consolidating the graduates of the basic departments at the leading companies, as well as the methodology for assessing the effectiveness of the activities of the basic departments both in terms of achieving the goals put forward by the university, and for solving the tasks of business structures.

3. Misunderstanding of the existing "Bologna" education system by the personnel services at companies.

Graduates-bachelors, often, are subject to the same requirements that were previously applied to graduatesspecialists, forgetting about changes in the educational program. Diplomas prepared by graduates are often performed fairly formally, and such a section as the practical application of results (one of the standard requirements for diploma of specialists) is absent. The time allocated for the thesis project is so small that the result is also small. The company is forced to invest additional funds for further vocational guidance of the graduate. At the same time, it is not clear what the graduatebachelor differs from graduates of secondary special educational institutions conducting teaching mass specialties (coders, system administrators, testers, technicians, etc.). To prepare such specialists, a more abridged program is sufficient.

\section{Some features of the current generation of students.}

Senior students, as a rule, do not have sufficient basic knowledge in the exact sciences to study courses related to the issues of intellectual data analysis (both because of problems of general school, and because of the programs themselves universities). Often they are unwilling to self-education and self-organization, they often rely on the search for "dubious" ready-made solutions on the Internet instead of independently searching for solutions, and also are not sufficiently motivated with respect to the aims of training. Many are forced to work, and not by profession, which also does not contribute to improving the quality of education.

\section{BASIC RESULTS AND DISCUSSION}

The lack of systematization in learning is a sure path to technological backwardness. It is obvious that without close cooperation of Universities and leading IT companies, the issues raised can't be successfully resolved, since it is necessary to closely link study programs with the needs of software industry, on the one hand, and with current trends and technological challenges in the IT area.

In order to match the skill levels developed in the existing professional standards (PS) with the level of higher education according to the Federal State Educational Standards (GEF) in April 2013, the order of the Ministry of Labor of the Russian Federation introduced the following reconciliations, presented in Table 2 .

TABLE II. CONFORMITY OF EDUCATION AND QUALIFICATION LEVELS

\begin{tabular}{|l|l|}
\hline \multicolumn{1}{|c|}{ Level of higher education } & \multicolumn{1}{c|}{ Qualification level } \\
\hline Bachelor & At least 5-6 \\
\hline Master's degree, specialty & Not less than 7 \\
\hline Highly qualified personnel & Not less than 8 \\
\hline
\end{tabular}


When formulating the professional tasks of graduates, one should refer to the formulations of generalized labor functions and labor functions of all professional standards selected by the developers to update the GEF. Fig. 1

At the same time, it is necessary to take into account that the list of professional tasks can be formulated much more widely than is assumed by a specific professional standard.

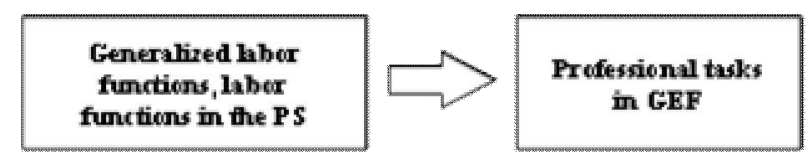

Fig. 1. Output professional tasks

So graduates of IT bachelor should solve a variety of diverse tasks from the creation and development to the introduction and operation of information systems in various application areas, implementing linking and integrating functions in the interaction of customers automation of information processing and engineering personnel solving technical problems. Specialists of the highest category are more focused on team design and technological work, management and research activities.

Obviously, in the field of information technology, staff is not only a "key resource", but also "the main ability" to effectively provide and consume IT services. The development of professional and educational standards contributes to the improvement of personnel and is the basis for the possibility of continuing studies. It is on this basis that study programs can be created, educational services can be developed and research conducted. As a result, it is advisable to use various forms of cooperation in joint work on the development of professional and educational standards, which have undoubted benefits for both young professionals and employers.

Programs for the development of new types of scientific and technical products, especially those intended for import substitution, should be supplemented by appropriate studies programs. The inconsistency of requirements is hampered by the improvement of the IT education system. Accordingly, for the qualitative development of the domestic IT industry, it is necessary to identify new and change existing professions, filling them with the necessary professional competencies [5]

As practical approaches to resolving issues, it can:

- development of software and technological equipment of companies and the organization of software especially free and domestic;

- development of proposals on combining studies programs with professional standards;

- forecasting new requirements to the content and quality of professional activity, defining the boundaries of professions;

- effective use of the resources of the basic departments for the organization of special courses and internships for students;

- participation in working groups to develop professional standards for new professions.
Examples of new professions include: Information Systems Architect, Virtual Architect, Neuro-Interface Designer, Big Data Modeler, Internet Communities Organizer

Today, the business community is interested in improving the IT education system for its fields of activity, but in order to fulfill the strategic tasks of our state to increase the number and quality of IT professionals, it is necessary to unite the efforts of all interested parties, including RAS organizations, line ministries, commercial structures and others, to search for models of interaction between education, business and the state.

\section{CONCLUSION}

So, Russia lags far behind developed countries in terms of the efficiency of doing business and organizing the work of personnel. The result of the activity of IT professionals is the basis for making managerial decisions, analyzing data, protecting information.

The country's leadership poses serious challenges for the reorganization of the IT industry, which for ten years should grow at a pace that is ahead of the world average growth rate of the IT industry. In this regard, it is extremely important to create such conditions for the development of human resources that would ensure satisfaction of not only the current but also the prospective demand for IT professionals in all sectors. The results of the survey [6] clearly show that the forecasted demand for 350,000 new highly qualified specialists by 2020 is still unattainable without major changes in the education system, starting with the school level.

In the conditions of rapid changes and the growth of uncertainties in modern labor markets, clearly defined competences acquire a special importance, which serve as the foundation for further professional growth and development of related specialties.

It is obvious that the improvement of the situation on the preparation of a new generation of IT specialists is possible only through the use of a systematic approach to solving existing problems involving all participants of the IT market under the leadership of the state.

This will require in the short term:

- increase the share of exact sciences in curricula and focus on advanced technologies;

- improve the quality of professional practice of students;

- form educational programs taking into to the immediate and future needs of society, focusing the modern student to the necessity of subsequent lifelong learning;

- conduct joint research of universities and IT companies in those applied IT areas that may be in demand in the short term and for which the current educational level of students may be sufficient.

\section{REFERENCES}

[1] S.A. Lebedev, D.G. Korneev, P.E. Ovchinnikov, N.Yu. Pustovoitov, Yu.F. Telnov, E.V. Pavlova, E.V. Romanova, "Professional standards of the programmer and the head of software development", Moscow: MESI, 2015, pp. 163 
[2] Professional standards. Ministry of Labor and Social Protection of the Russian Federation URL: http://profstandart.rosmintrud.ru/ ( Accessed: 20. 10. 2017 )

[3] Portal HeadHunter, Statistics, URL: https://stats.hh.ru/regioncomparison\#dateFrom $=1 \&$ dateTo $=9 \&$ profarea $\% 5 \mathrm{~B} \% 5 \mathrm{D}=1$ ( Accessed: 20. 10.2017)

[4] "Model of economic development: a technological component", Moscow, Free Economic Society of Russia. VIII Expert Session of the Coordination Club, August 28, 2017 URL: http://tass.ru/novostipartnerov/4514748 ( Accessed: 20. 10.2017)

[5] T.G. Orlova, "Professional Standards in IT: Reflection on the topic," Moscow: Open Systems, March 2014 URL: https://www.osp.ru/itsm/2014/03/13040067.html ( Accessed: 20. 10. 2017 )

[6] A.N.Zhilyaev and A.I.Oleynik , "Actual problems of preparation and developments of personnel potential in it branch," in Quality.innovation.education, Vol.12, 2015, pp. 9-22. 